\title{
PRÁTICAS DE ORGANIZAÇÃO E DIVULGAÇÃO DA PRODUÇÃO INTELECTUAL EM CIÊNCIA DA INFORMAÇÃO NO BRASIL
}

\author{
PRACTICES ON ORGANIZATION AND DIVULGATION OF THE \\ INTELECTUAL PRODUCTION IN INFORMATION SCIENCE IN BRAZIL
}

\begin{abstract}
Leilah Santiago Bufrem - leilah@ufpr.br
Doutora em Ciências da Comunicação pela USP e pós-doutora pela Universidad Autonoma de Madrid. Professora Titular do Departamento de Ciência e Gestão da Informação da Universidade Federal do

Paraná - Curitiba - PR.
\end{abstract}

\begin{abstract}
Resumo
Análise de questões teóricas sobre a construção de bases de dados, fundamentando-se em realizações práticas que vêm sendo desenvolvidas na constituição de uma fonte de informação, a base de dados BRAPCI. Discutem-se antinomias ou oposições entre o formalizado e o praticado, adotando-se como pressuposto a necessidade de crítica e autocrítica à prática e refletindo sobre a diferenciação entre os chamados indicadores quantitativos, aferíveis com a utilização de quantidades, medidas e números e os qualitativos, relacionados com qualidades avaliadas com a intermediação de construtos. Recomenda-se a complementaridade entre esses dois aspectos, quando da implementação de processos de avaliação de bases de dados.
\end{abstract}

Palavras-chave: Bases de dados. Indicadores. Ciência da Informação.

\section{INTRODUÇÃO}

A análise preliminar dos indícios de complementaridade entre aspectos qualitativos e quantitativos na construção de bases de dados referenciais motivou as reflexões comentadas neste artigo, também amparadas na crítica sobre a prática que vem sendo desenvolvida na constituição de um objeto de informação, a base de dados BRAPCI ${ }^{1}$. Trata-se, por um lado, de uma tentativa de analisar questões teóricas fundamentadas nas realizações práticas e, por outro, de discutir as antinomias ou oposições entre o formalizado e o praticado. Com esse intento, adota-se o pressuposto da necessidade de crítica e autocrítica à prática, para seu aperfeiçoamento, pois a metodologia para construção de uma base de dados, desenvolvida em determinado contexto social e em dado momento histórico, reflete as mudanças e contradições desse contexto, tanto em sua organização interna e indicadores de qualidade, quanto em suas aplicações.

\footnotetext{
${ }^{1}$ A Base de Dados Brasileira de Periódicos em Ciência da Informação, cuja construção teve seu início no ano de 2000, indexa regularmente artigos científicos de 27 revistas da área, desde o ano de publicação de 1970.
} 
A análise sobre indicadores de qualidade é parte das atividades de um processo em que se clarificam e distinguem a provisão da base e o seu monitoramento. Entretanto, considerar que os indicadores não são um fim em si mesmo, mas instrumentos práticos para a administração de bases de dados e tomadas de decisão, implica o encaminhamento dado ao seu processo de assunção, encaminhamento que, esse sim, volta-se aos propósitos ou fins para os quais se construiu o objeto. Esses orientam opções como as que se definem a partir dos critérios e do peso específico e representativo de cada elemento para sua constituição e manutenção.

O sentido dado a este estudo, embora não condicionado pelas forças denominadas por Chalmers (1991, p. 11) de progressistas, estimuladas pelos êxitos dos grandes experimentadores, tende a considerar a experiência como fonte de conhecimentos, pois seus impactos, promovidos pelos sucessos da prática, têm sido evidenciados na área de Ciência da Informação (CI). É inegável que o ciclo de transformações dos avanços científicos influenciou amplamente e com expressiva repercussão a condução teórico/prática das pesquisas operacionais e de avaliação em CI. Voltadas principalmente para a construção e aperfeiçoamento de modelos e sistemas de tratamento e disseminação da informação, elas usufruíram do prestígio dos avanços tecnológicos, fundados nas necessidades de acompanhar os resultados de investimentos de toda a ordem e na sua apreciação como marca por excelência da modernidade. Salienta-se a supremacia de uma mentalidade técnica, de uma tecnoestrutura e de uma tecnocultura, "enraizada em instituições, incluindo toda a vida social na burocratização, na secularização da religião, no individualismo e na diferenciação institucionalizada das esferas da ciência da arte e da moral" (LEMOS, 2004, p. 62).

Surgem, assim, expectativas de domínio progressivamente ampliado das tecnologias no fazer científico contemporâneo. Entretanto, a atual conjuntura investigativa da CI no Brasil revela o amadurecimento da postura crítica em relação ao que se está produzindo, especialmente quando se percebe a ampliação de estudos metacientíficos ou de avaliação dos modos de se fazer e compreender a ciência (BUFREM, 2007).

Assim, sem entrar na polêmica instaurada pela aceitação ou não dessa tecnoestrutura, o estudo aqui descrito procura definir possibilidades metodológicas e indicadores de qualidade não dependentes apenas de considerações quantitativas ou de modelos irrefutáveis, mas como encaminhamentos para a superação de uma visão genuinamente tecnológica.

\section{CONDUÇÃO DA PESQUISA}

A análise inicial deste estudo tenta definir as relações entre as construções científicas e o que se está realizando em sua concretização histórica. Representa um esforço metodológico ao destacar os traços comuns ou, ao contrário, diferenciados de um caso concreto em relação às abordagens científicas que vem prestando contas dos desenvolvimentos resultantes da interação teoria e prática. Para a sua realização, a realidade concreta é analisada como forma de possibilitar a unidade do pensamento e da ação. Marco da postura investigativa destaca-se a consciência das condições existentes nessa realidade. 
Esse processo ainda incipiente de revisão lógica e epistemológica, como vem sendo observado nos estudos sobre a literatura periódica científica na área de CI realizados pelo grupo de pesquisa Educação Pesquisa e Perfil Profissional ${ }^{2}$, abrange um amplo domínio de questões, especialmente voltadas à produção científica, incluindo-se entre elas a questão específica dos indicadores de avaliação das bases de dados que organizam essa produção.

As questões levantadas despontam de modo especial em relação à análise das revistas científicas, uma modalidade de estudo com presença significativa e reiterada na literatura voltada à produção de conhecimento e de sua representatividade em bases de dados. Ao definir as bases de dados como repositórios dos conhecimentos consensuais gerados pela ciência moderna, Sayão (1996) as considera constituintes da memória da ciência oficialmente aceita. Sua existência justifica-se especialmente pela necessidade que os pesquisadores e estudantes têm de informações sobre as fontes disponíveis para o domínio, sempre relativo, da literatura de sua área e dos meios existentes para difusão de seus próprios estudos. Além disso, a publicação científica tornou-se, em seu processo histórico, um instrumento indispensável tanto como meio de promoção acadêmica, quanto como modalidade de promoção e fortalecimento do ciclo criação, organização e difusão do conhecimento. Por conseguinte, sua contribuição social é um dos fatores que mais influenciam a realização deste estudo.

Como preocupação relativamente recente destinada à análise das pesquisas e produtos delas decorrentes, assim como dos métodos empregados para realizá-los, a produção e a consolidação de indicadores científicos vêm sendo praticadas em domínio complexo, dada a integração de campos do conhecimento e abordagens interdisciplinares para a concretização dos estudos. Assim, se por um lado ampliam-se as posições de exame, a partir de domínios que em dado momento são determinantes para o estudo, por outro, reduzem-se as certezas quanto à validade de indicadores já estabelecidos para um campo de trabalho científico. Assim, recorre-se à utilização de modelos de avaliação que considerem as estruturas específicas e as condições que tornam possível a concretização dos estudos em foco.

\section{O FOCO}

O acompanhamento da literatura sobre a produção científica, uma preocupação que vem se ampliando à medida que se registram formalmente as pesquisas na área de CI, impõe reflexões críticas sobre os modos de construção desse referencial, especialmente para aqueles cuja vocação seja o aprimoramento das bases de dados que os representam. Dessa forma, espera-se ampliar, com este estudo, as possibilidades de análise e interpretação das informações constantes em bases de dados com vistas à ampliação da

\footnotetext{
2 As pesquisas do grupo, criado em 2000 na Universidade Federal do Paraná e do Núcleo de Produção Científica da Universidade de São Paulo, coordenado pela Profa. Dra. Dinah Aguiar Población, integram-se aos esforços para compreender e evidenciar resultados de estudos na área de Ciência da Informação, cujo âmbito se amplia proporcionalmente ao dos novos campos de pesquisa, resultantes naturalmente das ramificações desse domínio.
} 
confiabilidade dos resultados de busca. O universo de questões relativas a essa preocupação é infinito se levadas em conta as facetas a ele relacionadas, em conseqüência das dimensões teórica e prática decorrentes do estudo. Assim, neste estudo, procurar-se-á delimitar a dimensão teórica às contribuições concernentes à prática concreta do grupo de pesquisa, voltada à construção de uma base de dados referencial de artigos de periódicos em CI produzidos no Brasil.

A base em questão, denominada Base BRAPCI, abrange dados referenciais de periódicos nacionais da área e teve como objetivo principal subsidiar o projeto Análise bibliométrica das tendências na pesquisa em informação no Brasil e Espanha, registrada em fontes nacionais e internacionais, firmado entre a Universidade Federal do Paraná (UFPR) e a Universidad Carlos III de Madrid. A base de dados atualmente disponibiliza referências de 4637 artigos publicados em 27 periódicos nacionais impressos e eletrônicos da área de CI, de 1970 a 2006.

Ao defender que qualquer trabalho científico, desenvolvido em determinado contexto social, e em dado momento histórico, reflete as mudanças e contradições desse contexto, tanto em sua organização interna ou método, quanto em suas aplicações (BUFREM, 1996), argumenta-se que o encaminhamento dado à pesquisa é resultante de opções ou perspectivas situadas concretamente. Como conseqüência desses elementos condicionantes, os estudos sobre revistas científicas situados na literatura recente, mais especificamente nos dez últimos anos, embora com marcante presença dos dados quantitativos como base empírica para reforçar argumentações, revelam uma tendência à análise e interpretação de caráter qualitativo, especialmente justificada pela complexidade de fatores intervenientes nas atividades de produção e divulgação científica.

Os estudos qualitativos, sobre essas transformações concretas, constatáveis na comunicação científica, são possibilidades ao desafio permanente de compreender e interpretar tendências e modos pelos quais as informações são publicadas, disseminadas, acessadas e usadas. Além disso, combinando-se características da WEB com o acesso a periódicos científicos e publicações, emerge o retrato de um ambiente volátil e dinâmico, a partir do qual é possível discutir sobre os elementos efetivos para a fertilização do processo de crítica e criação do conhecimento.

A descrição de uma política de informação é, na visão de Frohmann (1995), a exposição da genealogia de um regime de informação, pois ela revela as transformações cotidianas e as complexas e interativas práticas, ponto de vista que transcende a estreita concepção disciplinar de política da informação da área. Essa concepção defende que os instrumentos ou documentos da política de informação são elementos de um regime de informação. Descrever esse regime significa mapear o processo resultante da estabilização dos conflitos entre grupos sociais, interesses e discursos, com os correspondentes artefatos científicos e tecnológicos.

No sistema científico e tecnológico, a publicação é o principal indicador de excelência profissional e um meio para sua avaliação. Segundo Furtado (1981), 
esse fenômeno se verifica conforme critérios da aristocracia vigente, gerando dissonâncias, pois a avaliação e conquista de posições não dependem tanto da informação publicada, mas dos tipos de produtos e processos gerados, da rentabilidade econômica ou social envolvida e do prestígio conquistado. $\mathrm{O}$ próprio tipo de atividade e diferentes campos de atuação de cientistas e tecnólogos ocasionam conflitos conceituais e semânticos sobre a natureza da informação. A forma e o conteúdo da publicação variam nessas duas áreas, pelo fato de serem destinadas a leitores distintos, mas as dificuldades não estão limitadas à linguagem, pois podem se originar da própria estrutura institucional. Apesar das diferenças tipológicas entre cientistas e tecnólogos, um elemento comum é exigido, a competência.

Um dos indícios dessa competência revela-se na análise de citações, amplamente empregada no domínio da CI como indicador do trabalho científico nas diversas áreas do conhecimento. Essa metodologia, quando aplicada ao julgamento ou em grupos, sempre gerou problemas e críticas, o que motivou estudo de artigos selecionados por Motta (1983), na qual destaca e analisa opiniões de autores sobre elementos e relações de domínio que permeiam o processo. Por elas deduzse que o método tem sutilezas e limitações e que sua aplicação requer grande cuidado na interpretação dos dados sobre citações.

Crítica e autocríticas, entretanto, têm servido para fortalecer a prática da análise de citações, direcionando-a para formas de superação de suas contradições. Esse fenômeno é representado na literatura em artigos como o de Morales, Hooydonk e Ruiz (2000, p. 1, tradução nossa), a partir da idéia de Garfield, de que "a edição acumulativa de 10 anos dos índices de citações do Sience Citation Index (SCI) provavelmente incluirá todos os trabalhos científicos significativos conhecidos". Aproveitando o fato de que a base de dados Web of Science (WoS), introduzida recentemente pelo Institute for Scientific Information (ISI) inclui o SCI, os autores avaliam de forma preliminar a presença de autores e instituições cubanas, entre 1988 e $1998^{3}$. Uma observação dos autores, entretanto, expõe a limitação da representatividade de certas áreas e países e, conseqüentemente da utilidade da WoS. Autores que publicam somente em revistas cubanas têm sua representatividade muito limitada, já que somente uma revista científica, das mais de duzentas editadas em Cuba, é registrada atualmente nessa base de dados. Entretanto, o estudo comprova que o aumento gradativo de artigos publicados por cubanos e referenciados na WoS é significativo, assim como o indicador de associatividade dos autores cubanos. A grande lição conclusiva reporta que para lograr una avaliação verdadeiramente justa e objetiva do desempenho dos autores

3 Os dados foram extraídos das bases de dados Science Citation Index Expanded, Social Sciences Citation Index e Arts \& Humanities Citation Index produzidas pelo Institute of Scientific Information, Inc. (ISI), de Filadélfia, Pensilvânia, USA, (Copyright 1999), sob licença de exploração outorgada à Universidade de Ghent (Bélgica). 
e instituições, deve-se levar além da quantidade de artigos publicados, a quantidade de citações, o impacto acumulado e a avaliação dos pares (MORALES; HOOYDONK; RUIZ, 2000).

Essas premissas conduzem à valorização de instrumentos que representem fidedignamente a produção científica e respaldem o processo de sua recuperação. Estudos sobre limitações nessa busca de representatividade são indicativos dessa preocupação. Strehl (2005) evidencia, entre outras relações, as diferenças e variações nos valores do indicador do fator de impacto (FI) entre as diversas áreas do conhecimento, ao analisar os conceitos e os métodos relacionados com o seu uso pelo ISI para avaliar a produção científica publicada em periódicos. Resgata a história do FI, destacando variáveis que apresentam a maior influência sobre o FI, a densidade e o ritmo de obsolescência dos periódicos e discutindo as abordagens sincrônicas e diacrônicas para esse tipo de estudo, como o índice de citação imediata, a meia-vida das citações e o estudo da idade de referências citadas. Ao destacar o sistema de avaliação científica brasileiro e o papel do SciELO na formulação de indicadores bibliométricos, o estudo vislumbra a complexidade desse processo em um país cujas estruturas ainda estão se firmando nesse setor.

Considerações sobre indicadores também são realizadas por Rummler (2006), ao levantar especialmente exemplos que ilustram possibilidades de aplicação do indicador relativo de dispersão (Índice de Dispersão Segmentar - IDS) para o estudo comparativo de obras, periódicos, autores, métodos, técnicas, assuntos, e vocábulos, entre outras possibilidades. Partindo do princípio de que a diversidade de localização dos suportes de uma informação provoca sua dispersão, se isso ocorre com a informação citada na literatura, configura-se impacto bibliográfico. Dessa forma, um indicador de dispersão pode constituir ferramenta útil para avaliação desses fenômenos. $\mathrm{O}$ autor demonstra a modelagem de um indicador relativo de dispersão (IDS), que considera a ocorrência desta, segundo diferentes níveis de distribuição (macro, meso e/ou microdispersăo) referentes a unidades de análise bibliométricas, cienciométricas, informétricas, tecnométricas ou similares.

As iniciativas e ferramentas utilizadas para avaliação da produção científica se completam, entretanto, com instrumentos de informação ágeis e efetivos, sujeitos, por sua vez a avaliações criteriosas, respaldadas em indicadores de qualidade.

\section{ASPECTOS ORIENTADORES DA CRÍTICA}

Como fundamento da crítica à prática que se está implantando, definem-se aspectos que, por sua importância, merecem atenção especial: o universo ou corpus de uma estrutura de análise, neste caso especial, uma base de dados; os elementos representativos de cada um dos itens do corpus, o delineamento da máscara ou espelho que comportará esses itens e a qualidade, atualização, exatidão e estilo do conteúdo.

As contribuições de Unger e Freire (2006, p. 110) partem uma visão da relevância da informação na sociedade contemporânea e do propósito de produzir uma informação que alcance seus possíveis usuários, razão pela qual os profissionais da informação 
deveriam considerar, para o desenvolvimento de suas atividades: o contexto sócioeconômico-cultural (regime) onde se inserem o agregado e seus estoques de informação e o grupo de usuários que lhes interessa; um modelo de sistema de informação que atenda às características desses usuários potenciais e uma linguagem documentária que melhor represente o conhecimento oculto nos estoques de informação, de modo a diminuir as barreiras na comunicação entre o sistema e seus usuários.

\subsection{Universo ou corpus}

$\mathrm{O}$ conceito de base de dados envolve as questões sobre a natureza e a finalidade do seu conteúdo. O desenvolvimento do acervo define-se a partir da extensão e profundidade na cobertura temática, segundo os níveis estabelecidos no planejamento. Dessa definição decorrem as atividades relativas tanto à sua construção quanto à sua manutenção, acesso e uso. Ao permear o processo de planejamento de uma base de dados, a presença do usuário impõe-se para a definição dos propósitos e como orientação para avaliação dos processos e do produto gerado. O corpus deve ser, portanto, representativo das necessidades reais e potenciais da comunidade usuária.

Segundo García Lopez (2007, p. 174), poderão ser levados em conta, para avaliação de uma base de dados, aspectos como: grau de cobertura ou alcance temático, com indicação da área temática e revistas indexadas; cobertura geografia e lingüística; grau de inclusão, incluindo-se tipos de documentos; estrutura, incluído-se número de campos, sua utilização ou não para indexação e tamanho e número de registros, além do nível de crescimento, ou seja, quantidade de itens novos a cada unidade de tempo.

Esses indicadores evidentemente devem ser levados em conta a partir de um estudo das necessidades dos utilizadores da base, como orientação para sua criação, implantação e atualização. A outra face da avaliação pode ser realizada a partir das análise de uso e satisfação dos usuários/clientes de uma base.

Nesse sentido, a análise do uso da base de dados "AgeLine", pelos usuários da Biblioteca da Faculdade de Educação da UNICAMP (SANTOS, 1999), enfoca principalmente as categorias de usuários da base de dados, seus projetos, propósitos e assuntos de pesquisa, analisando a importância do uso da base como indicador para renovação de sua assinatura.

Analogamente, o estudo de Gato e outros (2004) elabora análise bibliométrica de uso da coleção de periódicos, evidenciando o papel fundamental que as bibliotecas da Embrapa desempenham na estrutura organizacional e na estratégia da empresa, como interface entre a geração e a disseminação do processo de pesquisa, desenvolvimento e inovações

(PD\&I). Resultados apontaram a efetiva utilização de periódicos e demonstram o efeito do acervo da biblioteca para as atividades de PD\&I na Unidade, no período estudado (1990-1999).

Considerando-se que para a definição de um corpus ou conjunto de componentes de uma determinada base é necessário também estabelecer o recorte fundado no interesse e propósito dessa base, a tarefa pode implicar a rejeição de parcela da realidade, 
constituindo-se em jogo dialético entre a extensão de elementos disponíveis e a seleção dos elementos pertinentes e adequados às necessidades.

Portanto, também as estatísticas enquanto reapresentam e representam uma realidade, são intencionalmente vocacionadas. Essas representações, como argumenta Guizzardi Filho (2004), são produzidas a partir da definição de recortes que procuram simplificar os aspectos do mundo, os quais são os objetos de estudo. Os recortes facilitam a compreensão desses aspectos, e expressam-se, por exemplo, nas categorias de uma análise de conteúdo, na definição de indicadores e critérios e, obviamente, como o nome indica, organizam-se em detrimento de uma realidade não contemplada no recorte. $\mathrm{O}$ que as estatísticas visualizam são números que representam conjuntos com as mesmas características expressas em classificações idealizadas pelos pesquisadores que as constroem. Para que as estatísticas possam ser utilizadas, essas escolhas precisam, portanto, estar explícitas, revelando-se nas classificações e conceitos associados à representação, nos segmentos do universo que são escolhidos como objeto de estudo, nos erros que estão associados aos resultados que são divulgados. Se isso não ocorrer, o uso da estatística pode resultar no oposto do que se espera dela, que é o conhecimento.

Essa precisão de intenções, se transferida para a questão abrangência de uma base de dados, releva a importância da definição criteriosa do recorte, da amostra ou da explicitação do universo. Os critérios de Goldstein $\operatorname{Jr}(1999$, p. 8) para a indexação de periódicos referem-se especialmente à regularidade de publicação, composição do corpo editorial, rigor do processo de revisão, qualidade gráfica, participação do título no cenário internacional, abrangência de distribuição, possibilidade de aquisição e citações.

As citações dos periódicos em outros textos têm sido objeto de análise e comprovam efetivamente sua importância como elementos estimuladores da produção científica. Segundo Mueller (1999, p. 3), a inclusão dos periódicos em índices e bases internacionais garante aos artigos indexados a visibilidade necessária, facilitando a busca dos autores por literatura recente e aumentando a chance de serem lidos e citados e conseqüentemente cumprindo o ciclo leitura, produção, citação, leitura.

Vale ressaltar que entre os artigos analisados sobre o tema, quando da caracterização dos periódicos científicos nacionais, foi decisiva a leitura de Ohira, Sombrio e Prado (2000), sobre as características e disponibilidade desses veículos da produção científica especializada.

A construção da base BRAPCI, como ilustração da problemática referente ao universo a indexar, teve critérios orientadores para inclusão dos periódicos representativos da área de CI. Para a identificação dos títulos indexados foi consultada a Lista Qualis de Periódicos da área de Ciências Sociais Aplicadas, disponibilizada pela Coordenação de Aperfeiçoamento de Pessoal de Nível Superior (CAPES), no endereço eletrônico: http://www.capes.gov.br. Esse expediente, aliado à busca no Catálogo Coletivo Nacional (CCN) e nas bibliotecas universitárias e institucionais, ensejou uma visão geral da produção editorial da área e a identificação dos títulos que: 
a) não são mais publicados, caso da Arquivo \& Administração; Estudos Avançados em Biblioteconomia e Ciência da Informação; Informare Cadernos do Programa de Pós-graduação em Ciência da Informação; e Revista de Biblioteconomia de Brasília, que foi publicada normalmente até 1990, encerrou no período de 1991 a 1994, foi retomada em 1995 e novamente interrompido a partir de 1997;

b) mudaram de nome, como a Revista da Escola de Biblioteconomia da UFMG, que passou a se chamar Perspectivas em Ciência da Informação; o periódico Revista de Biblioteconomia \& Comunicação, que passou a se chamar Em Questão: Revista da Faculdade de Biblioteconomia $e$ Comunicação da UFRGS; a Revista de Biblioteconomia do Maranhão foi substituída pela Infociência; a Revista do Departamento de Biblioteconomia e História mudou o nome para BIBLOS: Revista do Departamento de Biblioteconomia e História; e o periódico eletrônico ETD - Educação Temática Digital, que inicialmente era Revista Online da Biblioteca Prof. Joel Martins;

c) foram interrompidos por um período e voltaram a ser publicadas com acréscimos no nome, como a Revista Brasileira de Biblioteconomia e Documentação, que retornou como Revista Brasileira de Biblioteconomia e Documentação: Nova Série.

d) mudaram de endereço, caso da revista Ciência da Informação, que inicialmente era publicada no Rio de Janeiro e que, a partir de 1980, passou a ser publicada em Brasília;

e) alteraram a periodicidade, como a Ciência da Informação; Perspectivas em Ciência da Informação e Transinformação, que inicialmente eram semestrais e atualmente são quadrimestrais. Caso também da Informação \& Sociedade: Estudos que de anual mudou para semestral e atualmente é quadrimestral e da Revista Brasileira de Biblioteconomia e Documentação, que iniciou como publicação trimestral e agora é semestral.

Nos três primeiros anos da implantação do projeto (2000-2003), foram levantados os títulos dos periódicos da área (13 títulos) e, paralelamente, realizada busca no acervo da Biblioteca do Setor de Ciências Sociais Aplicadas (BSCSA) da Universidade Federal do Paraná, onde foram verificados os periódicos do acervo físico, relacionados à área de CI. Os fascículos não encontrados foram solicitados aos editores ou, após localização no $\mathrm{CCN}$, a outras bibliotecas, para que fossem preenchidos os dados de acordo com os campos definidos para a sua representação na base.

Paralelamente a esse trabalho têm sido realizadas análises específicas sobre as características temáticas, metodológicas e formais dessa literatura. Foi significativamente ampliada a quantidade de títulos selecionados, de 13 iniciais para 274 títulos e a preocupação, com a completeza da base, reflete-se no acervo

\footnotetext{
${ }^{4}$ Arquivística.net; Arquivo \& Administração; BIBLOS: Revista do Departamento de Biblioteconomia e
} 
da BSCSA, como depositária dos periódicos da área, repercutindo na comunidade interna e externa, cujas contribuições ao aperfeiçoamento e crescimento da base vêm se expressando em comunicações efetivadas entre ela e a equipe do projeto. Importa salientar, nesse caso, que a qualidade almejada não se pode expressar apenas no valor numérico dos artigos indexados na base, mas principalmente na busca da veracidade quantitativa e na honestidade com que se estabelecem critérios, se comunicam e disseminam os resultados do que se pode denominar de acervo efetivamente controlado.

\subsection{Elementos representativos}

Embora reconhecida como prática legítima e necessária, a revisão dos critérios para representação de documentos em bases de dados referenciais depende de uma compreensão dos elementos articuladores entre a estrutura e a percepção das necessidades e relações que se definem a partir de indicadores reconhecidos para sua construção. A consideração dos aspectos da análise documentária, caracterizados por Kobashi (1996) em relação aos seus referenciais teóricos, conceituais e metodológicos mais importantes, destaca a natureza de seu diálogo com as disciplinas que têm o texto como objeto.

A qualidade das tarefas correspondentes à indexação e ao resumo é proporcional, segundo Moreiro González (2002), à satisfatória recuperação da informação e a uma adequada explicação dos conteúdos aos usuários. A revisão dos critérios, nesse caso, aplica-se à qualidade dos produtos originados dos processos de análise documentária $\mathrm{e}$ de conteúdo. Por certo esses critérios não se limitam a uma medição estatística e numérica dos fatores qualitativos, somente apreciáveis mediante observação e juízos pessoais centrados em tarefas de identificação e avaliação de repertórios, da qualificação do analista, da existência de normas e diretrizes para sua organização e do tipo de linguagem de indexação. Esses fatores qualitativos se expressam, por sua vez, no grau de reutilização dos resumos e da indexação de origem, na forma de traslado da superestrutura, na qualidade técnica e na profundidade de análise. Junto a unidades de medida, devem ser levados em conta indicadores como de cobertura e solapamento dos repertórios, coerência, densidade informativa, exaustividade, legibilidade, pertinência e profundidade, entre outros.

Os problemas relativos à exaustividade, especificidade e coerência da indexação tornam-se cruciais para o gerenciamento e recuperação de informações nas bases de

História; Cadernos de Biblioteconomia; Ciência da Informação; Comunicação \& Informação; DataGramaZero; Em Questão: Revista da Faculdade de Biblioteconomia e Comunicação da UFRGS; Encontros Bibli; Estudos Avançados em Biblioteconomia e Ciência da Informação; ETD - Educação Temática Digital; Inclusão Social; Infociência; Informação \& Informação; Informação \& Sociedade: Estudos; Informare: Cadernos do Programa de Pós-Graduação em Ciência da Informação; Liinc em revista; Perspectivas em Ciência da Informação; Revista ACB: Biblioteconomia em Santa Catarina; Revista Brasileira de Biblioteconomia e Documentação; Revista da Escola de Biblioteconomia da UFMG; Revista de Biblioteconomia \& Comunicação; Revista de Biblioteconomia de Brasília; Revista Digital de Biblioteconomia \& Ciência da Informação; Revista do Departamento de Biblioteconomia e História; Revista Online da Biblioteca Prof. Joel Martins; Transinformação. 
dados bibliográficos (NUNES; FREITAS, 1997). Em estudo realizado sobre uma amostra de 422 registros, correspondentes a igual número de documentos integrantes do acervo, distribuídos por todas as áreas do conhecimento, Nunes e Freitas comparam cada registro da amostra com o próprio documento e com instrumentos de indexação, verificando o comportamento das variáveis exaustividade, especificidade e coerência na Base de Dados do Núcleo de Informação e Documentação da Fundação Universidade do Rio Grande (NIF/FURG), que abrange parcialmente os acervos das bibliotecas desta Universidade e da Universidade Federal de Pelotas (UFPEL). Verificou que o nível de exaustividade é baixo, situando-se em 3,9 cabeçalhos de assunto, 1,54 descritores e 0,58 termos livres por registro, respectivamente. $O$ princípio da especificidade freqüentemente não é observado, verificando-se, inclusive, a adoção concomitante de termos genéricos e termos específicos para um mesmo item. A coerência interindexadores aproxima-se dos valores encontrados na literatura, situando-se num índice médio global de 0,23 para os pares de coerência encontrados. Esses resultados evidenciam a necessidade de se adotar instrumentos de indexação especializados e procedimentos de rotina automatizados para o controle do vocabulário.

Permeiam essa problemática questões terminológicas em áreas específicas, uma vez que vocabulários próprios partem de setores diferenciados da teoria e da prática. Os resultados da análise de Moraes (2007) sobre a terminologia aplicada à área de saúde levaram-na a concluir sobre a validade do uso da análise terminológica como um dos instrumentos para a reordenação dos Grupos de Pesquisa dentro das linhas de pesquisa da Fundação Osvaldo Cruz, assim como do seu uso como instrumento de avaliação da produção científica. Esses processos contribuem para maior integração científica institucional, de maneira estratégica e econômica. A terminologia empregada pelos pesquisadores para identificação dos temas de seus Grupos de Pesquisa, registrados junto ao Conselho Nacional de Desenvolvimento Científico e Tecnológico, foi também empregada como um instrumento na reordenação das Linhas de Pesquisa da Fundação Oswaldo Cruz, assim como indicador qualitativo para a avaliação da produção científica institucional. Esses dois processos foram desenvolvidos pelo Departamento de Estudos em Ciência e Tecnologia do Centro de Informação Científica e Tecnológica, em parceria com representantes de outras Unidades da Instituição. Uma análise comparativa apontou as divergências existentes entre a terminologia empregada pelos pesquisadores, a Tabela de Áreas do Conhecimento do Conselho Nacional de Desenvolvimento Científico e Tecnológico, os Descritores em Ciências da Saúde desenvolvidos pelo Centro Latino Americano e do Caribe de Informações em Ciências da Saúde e o Tesauro de Manguinhos.

O fenômeno da inconsistência terminológica foi percebido por Oddone e Meirelles (2006) quando da análise sobre o desempenho e funcionalidade do Portal de Periódicos da CAPES na interação com os hábitos dos usuários, para aferir sua utilidade enquanto repertório bibliográfico e ferramenta de acesso à informação. Ao descrever as etapas preliminares da investigação, o artigo assinala os obstáculos encontrados nesse processo e os meios para superá-los. Lançado em novembro de 2000, o portal passou a se constituir em instrumento de disseminação da informação científica, recurso indispensável à produção científica e tecnológica nacional. A consulta à literatura por 
indicadores que orientassem a exploração deste objeto de estudo deparou-se com generalizada falta de consistência terminológica e conceitual nas raras pesquisas produzidas em CI sobre o tema, ao menos em língua portuguesa. Só após recorrer à literatura de outras áreas, os autores chegaram às noções de legibilidade e usabilidade, definindo-as como as de maior potencial no estudo do problema.

Esse tipo de divergência ocorre de modo peculiar quando da construção de uma base de dados referencial de artigos de periódicos. A construção automática de uma lista de termos implica a aceitação de palavras-chave cujas origens são diversas, isso é, são provenientes de propostas de indexação dos editores, com critérios diferenciados, assim como de termos atribuídos por autores que utilizam linguagem natural para representar seus textos. Considerando-se a discussão sobre o mérito da linguagem natural, sua precisão e especificidade e os estudos comparativos sobre buscas em textos livres versus termos controlados, parece conveniente, conforme sugere Lancaster, acrescer ao sistema de construção da base um tipo de "tesauro de busca" (1993, p. 215).

A experiência com a base BRAPCI, cuja construção partiu de uma recuperação histórica dos primeiros exemplares das revistas componentes, demonstrou a conveniência de se acompanhar a atribuição das palavras-chave já existentes. Em fase posterior de padronização, foi realizada uma leitura comparativa com descritores padronizados do tesauro ASIS $^{5}$, a partir da qual foram acrescentados os termos que pudessem facilitar a busca automática e padronizados outros para a consistência da terminologia.

\subsection{Indicadores de desempenho}

Reflete-se na literatura uma realidade caracterizada em termos de inconsistência terminológica no que se refere a indicadores que permitam a análise sobre a funcionalidade de instrumentos de informação. A própria diferenciação entre os chamados indicadores quantitativos, aferíveis com a utilização de quantidades, medidas e números e os qualitativos, relacionados com qualidades que não se podem medir sem a intermediação de construtos (GARCÍA LÓPEZ, 2007, p. 118), já indica a necessária complementaridade entre esses dois aspectos, quando da implementação de processos de avaliação.

A avaliação dos recursos eletrônicos e dos seus efeitos na disseminação e uso da informação é uma ausência sentida por Saracevic e Covi (2000), cuja crítica aponta para a complexidade da tarefa de avaliar bibliotecas digitais, o que se reflete na incipiencia do estado-da-arte dos conceitos concernentes ao propósito. O texto contribui para o esclarecimento da problemática, indicando um conjunto de elementos ou construtos passíveis de integrar um processo de avaliação (Quadro 1).

5 O Tesauro do American Society for Information Science and Technology (ASIS), utilizado para criação e manutenção da base foi traduzido por Eunice Istschuk orientada pelo professor Ulf Gregor Baranow. A lista de termos do ASIS foi padronizada pela professora Cecília Licia Silveira e Medina Fabian, 


\begin{tabular}{|c|c|}
\hline ELEMENTOS & INDICADORES DE AVALIAÇÃO \\
\hline Coleções digitais, recursos & $\begin{array}{ll}\text { - } & \text { seleção, coleta, obtenção, mídia; } \\
\text { - } & \text { distribuição, conexão, links; } \\
\text { - } & \text { organização, estrutura, armazenamento; } \\
\text { - } & \text { interpretação, representação, metadados; } \\
\text { - } & \text { preservação, persistência. }\end{array}$ \\
\hline Acesso & $\begin{array}{ll}\text { - } & \text { intelectual; } \\
\text { - } & \text { físico; } \\
- & \text { distribuição; } \\
- & \text { interfaces, interação; } \\
\text { - } & \text { pesquisa, recuperação. }\end{array}$ \\
\hline Serviços & $\begin{array}{ll}\text { - } & \text { disponibilidade; } \\
\text { - } & \text { alcance dos serviços disponíveis; } \\
\text { - } & \text { disseminação; } \\
- & \text { distribuição; } \\
- & \text { assistência; } \\
\text { - } & \text { sistema de referência. }\end{array}$ \\
\hline Uso, usuário, comunidades & $\begin{array}{ll} & \text { acessibilidade; } \\
\text { - } & \text { disponibilidade; } \\
- & \text { facilidade; } \\
- & \text { usabilidade; } \\
- & \text { satisfação; } \\
- & \text { inteligibilidade; } \\
- & \text { operacionalidade. } \\
\end{array}$ \\
\hline $\begin{array}{l}\text { Segurança, políticas de privacidade, aspectos } \\
\text { legais, licenças }\end{array}$ & $\begin{array}{l}\text { - } \quad \text { autoridade, copyright; } \\
-\quad \text { estabelecimentos de normas e diretrizes; } \\
\text { segurança de acesso. }\end{array}$ \\
\hline Gerenciamento, operações, equipe & $\begin{array}{ll}- & \text { compromisso; } \\
- & \text { responsabilidade; } \\
- & \text { esforço; } \\
- & \text { competência. }\end{array}$ \\
\hline Custos, economia & - adequação. \\
\hline $\begin{array}{l}\text { Integração, cooperação com outros recursos, } \\
\text { bibliotecas, ou serviços }\end{array}$ & - $\quad$ interoperabilidade. \\
\hline
\end{tabular}

Quadro 1 - Elementos para avaliação de serviços ou produtos Fonte: Adaptado de Saracevic e Covi (2000).

Os autores advertem, entretanto, para a impossibilidade de cobrir todos os possíveis elementos de avaliação, especialmente porque se referem à realidade das bibliotecas digitais, cujos propósitos são mais abrangentes, incluindo estrutura e apresentação mais complexas e permitindo o acesso remoto por meio de rede e utilização simultânea pelos usuários, de produtos e serviços característicos de uma biblioteca física.

A aplicação dessas recomendações às bases de dados requer uma adaptação específica

baseada em lista de termos do apêndice do estudo de Eunice Istschuk.

Enc. Bibli: R. Eletr. Bibliotecon. Ci. Inf., Florianópolis, n. esp., $1^{\text {o }}$ sem. 2008 
ao tipo de produto concreto que se deseja obter e dos serviços a disponibilizar. Por conseqüência, a avaliação de uma base de dados pode selecionar entre esses elementos o que avaliar. Em outros termos, uma avaliação deve especificar claramente que indicadores são avaliados, reconhecendo as ênfases que orientam o processo e que cada avaliação sempre poderá deixar de fora algum elemento da estrutura e funcionamento de uma biblioteca digital.

Diante das sugestões teóricas, recomendam-se cuidados especiais aos responsáveis pelas bases de dados de alimentação continuada relativamente aos propósitos teóricos que fundamentam sua prática, especialmente porque sobre ela influem formas concretas de produção e preservação que se transformam em ritmo muito acelerado e muitas vezes entravam o acompanhamento crítico do produto.

\subsection{Qualidade, atualização, exatidão e estilo do conteúdo}

A qualidade de uma base de dados referencial depende não apenas do conteúdo e da sua adequada representação, mas da atualização periódica dos dados, dentro dos padrões estabelecidos para o acompanhamento das publicações, sua padronização, controle de qualidade e segurança.

O processo de atualização tem duas vertentes orientadas por decisões políticas e que se referem, a primeira, ao conteúdo da base, dependente das atividades de inclusão e atualização dos dados e, a segunda, ao aprimoramento das tecnologias utilizadas para a otimização do bom emprego de seu potencial pelo usuário, tarefas que requerem abordagem interdisciplinar, envolvendo conhecimentos especializados.

O critério inicial da Base Futura, por exemplo, foi incluir informação bibliográfica de todo e qualquer documento (impresso e/ou eletrônico) indexado, nas várias fontes de informação da área, com um ou mais dos seguintes termos: biblioteca do futuro, biblioteca virtual, biblioteca digital, biblioteca eletrônica, biblioteca biônica, biblioteca sem paredes, biblioteca de realidade virtual ou cibernética. Em sua fase inicial, as únicas restrições feitas foram quanto à data de publicação do documento, cobrindo o período de janeiro de 1995 a junho de 1997 e a língua, incluindo-se documentos em inglês, francês, espanhol, e português (FERREIRA et al, 1997).

O caso relata a decisão por abrangência mais dilatada quanto ao tipo de documento, em detrimento da extensão do período, sem dúvida uma decisão política decorrente das condições concretas quando da construção de uma base, tais como, previsão em maior ou menor prazo do projeto, equipe de colaboradores, finalidades do produto, existência ou não de produtos similares, características e perspectivas de futuro.

Essas mesmas características condicionam as atividades de atualização e padronização do conteúdo, concretizado também em dependência de um trabalho regular da equipe do projeto e das pesquisas periódicas para inserção, caracterização e padronização dos dados.

$\mathrm{Na}$ outra vertente do processo, o trabalho de adaptação e aperfeiçoamento contínuo da 
base, requer a consideração de indicadores tais como dispositivos de saída dos dados, as informações disponibilizadas, a visualização da informação, o retorno possível do usuário, o comportamento do sistema e os sistemas de apoio à base. É precisamente na comunicação e na necessidade de que ambas as partes utilizem os mesmo códigos que reside a chave do arco de êxito ou fracasso da interação, segundo García López (2007, p. 184).

Nesse processo, a visualização implica mais do que simplesmente o ato de olhar, segundo concepção de García López $(2007,184)$, a partir de Dürsteler (2002), uma vez que é uma construção mental, próxima do conhecimento, portanto, uma apreensão intelectual. Se o entendimento significa a contextualização, inclusão e interiorização de algo, é um ato que se modifica e modifica a estrutura nocional dos sujeitos.

A qualidade das interfaces de uma base de dados é, portanto, um fator de estímulo conducente e mobilizador desse entendimento. Propostas de metáforas visuais ou técnicas de visualização têm sido desenvolvidas, tais como as representações hierárquicas ou em rede, representações de dispersão e mapas ou ainda, o muro de perspectiva, árvores, lentes e browser, com os distintos focos que permitem. Nenhuma delas, entretanto, dispensa, quando se projeta a qualidade na relação ser humano/máquina, a recorrência a técnicas de transformação visual, como propõem Gutwin e Fedak citados por García López (2007, 185-187).

As contribuições da literatura, sem dúvida, esclarecem aspectos da prática concreta relacionada às fases de planejamento, construção, atualização, padronização, disponibilização e utilização de bases de dados. Entretanto, por mais atuais e abrangentes que sejam seus ensinamentos apenas sugerem a complexidade das estruturas que suportam esse tipo de realização.

\section{CONSIDERAÇÕES FINAIS}

A complexidade revelada quando se pretende analisar, de forma mais abrangente os indícios de complementaridade entre aspectos qualitativos e quantitativos na construção de bases de dados referenciais envolve aspectos decorrentes das relações entre propósitos e expectativas, quantidade e qualidade, extensão e intensão, limites de espaço e tempo.

As conquistas concretas quando se realiza uma experiência como a construção de uma base, com respaldo e recursos restritos, motivou as reflexões comentadas neste artigo, também amparadas na crítica sobre a prática que vem sendo desenvolvida na constituição de uma fonte de informação, a base de dados BRAPCI.

Espera-se que esta tentativa de analisar questões teóricas fundamentadas nas realizações práticas e de discutir as antinomias ou oposições entre o formalizado e o praticado possa contribuir para o aperfeiçoamento, não somente dessa base específica, mas que a metodologia desenvolvida reflita as mudanças e contradições do contexto, tanto em sua organização interna e indicadores de qualidade, quanto em suas aplicações. 
Como fundamentos da crítica à prática revelam-se aspectos que, por sua importância, adquirem especial relevo.

Na definição de um corpus ou conjunto de conteúdos componentes de uma determinada base, destaca-se o estabelecimento do recorte, fundado no interesse social e propósito de um instrumento de recuperação da informação. Essa relação entre produção e utilização responde a questões como o valor de uso por um determinado grupo ou sociedade, ou ainda sobre os resultados do instrumento relativos à democratização da informação.

Para que se possam analisar os elementos representativos de cada um dos itens do corpus destacam-se indicadores da estrutura de relações lingüísticas utilizada para condensar as informações, de modo a oferecer um conjunto mínimo de dados que permitam uma recuperação do almejado, no conjunto de elementos do conjunto. A seleção dos itens representativos do corpus atesta a qualidade dos processos de representação informacional, especialmente levando-se em conta: a compatibilização dos termos livres utilizados pelos autores com vocabulários controlados; $\mathrm{o}$ estabelecimento de uma estrutura ontológica; a análise dos termos procurando-se definir as relações lógico-semânticas; a padronização e inclusão de termos quando insuficientemente representados e a construção de critérios para atendimento do perfil de interesse do usuário da área. Essa realização concreta revela uma natureza especial no diálogo com as demais disciplinas que têm o texto como objeto.

Para a adaptação necessária aos diferentes perfis de usuários de uma base, o delineamento da máscara ou espelho que comportará esses itens e as interfaces pertinentes a esses perfis, exige-se constante atualização, exatidão, conformação de estilo apropriado ao conteúdo e adaptação aos usos.

As questões levantadas a partir desses indicadores acolhem os ensinamentos encontrados na literatura, mas adquirem maior pertinência se relacionadas à prática concreta, sugestiva da complexidade das estruturas de apoio a esse tipo de realização. Exigem, portanto, a definição e renovação de indicadores das condições que, se espera, determinem a qualidade, tanto em relação ao processo de construção do produto, quanto aos resultados tangíveis relativos ao seu uso e ao processo de socialização das fontes de informação de qualquer natureza. O domínio das tecnologias no fazer científico contemporâneo, portanto, depara-se, na prática científica da área de CI no Brasil, com uma postura crítica em relação ao que se está construindo, neutralizando os indesejáveis excessos da técnica pela técnica. Assim, desviando-se da polêmica instaurada pela denominada tecnoestrutura, este estudo procurou analisar questões metodológicas e indicadores de qualidade, como encaminhamentos para a realização prática e as políticas de avaliação.

\section{REFERÊNCIAS}

BUFREM, L. S. Linhas e tendências metodológicas na produção discente do Mestrado em Ciência da Informação do Instituto Brasileiro de Informação em Ciência e Tecnologia: Universidade Federal do Rio de Janeiro (1972-1995). Curitiba, 1996. 386 f. Tese (Professor Titular) - Departamento de Biblioteconomia, Setor de Ciências Humanas, Letras e Artes, 
Universidade Federal do Paraná, 1996.

BUFREM, L. S. Opções metodológicas na produção científica em Ciência da Informação. Universidade Federal do Paraná. Curitiba, 2007. Projeto de pesquisa.

CHALMERS, Alan. ¿Qué es esa cosa llamada ciencia?: una valorización de la naturaleza y el estatuto de la ciencia y sus métodos. 9. ed. Madrid: Siglo veintiuno, 1991. 246 p.

DÜRSTELER, Juan. Information visualization, what is it all about? Inf@Vis! The digital magazine of InfoVis.net , n. 100 , 2002. Disponível em: $<$ http://www.infovis.net/printMag.php?num=100\&lang=2>. Acesso em: 22/08/2006.

FERREIRA, Sueli M. S. P.; KIYOTANI, Normanda Miranda; PARKER, Abel; SANTOS, Paola de Marco Lopes. FUTURA: uma base de dados sobre a biblioteca do futuro. Ciência da Informação, v. 26, n. 2, 1997.

FROHMANN, B. Taking information policy beyond information science: applying actor network theory. [London]: [s.n.], 1995. Disponível em:

$<$ http://www.ualberta.ca/dept/slis/cais/frohmann.htm> Acesso em: 08/09/2007.

FURTADO, João. Conceitos e tipologia em ciência e tecnologia e sua influência na publicação de informações. Ciência da Informação, Brasília, v. 10, n. 1, p. 13-18, 1981.

GARCÍA LÓPEZ, Genaro Luis. Los sistemas automatizados de acceso a la información bibliográfica: evaluación y tendencias en la era de Internet. Salamanca: Ediciones Universidad de Salamanca, 2007.

GATO, Rubenise Farias et al. Gestão da informação na Embrapa Amazônia Oriental: uso relativo versus uso efetivo da literatura técnico-científica agropecuária periódica - 1990-1999.

Ciência da Informação, Brasília, v. 33, n. 2, p. 83-90, 2004.

GOLDSTEIN JR, Leonardo. Pesquisa: da produção à divulgação. Jornal da UNICAMP, Campinas, fev. 1999. p. 8.

GUIZZARDI FILHO, Osvaldo. Estatísticas, representação e conhecimento. Transinformação, Campinas, v. 16, n. 2, p. 163-170, 2004.

KOBASHI, Nair Yumiko. Análise documentária e representação da informação. Informare: Cadernos do Programa de pós-graduação em Ciência da Informação, Rio de Janeiro, v.2, n. 2, p. 5-27, 1996.

LANCASTER, F. W. Indexação e resumos: teoria e prática. Brasília: Briquet de Lemos/Livros, 1993.

LEMOS, André. Cibercultura, tecnologia e vida social na cultura contemporânea. 2. ed. Porto Alegre: Sulina, 2004.

MORAES, Alice Ferry de. Terminologia como indicador qualitativo. Transinformação, Campinas, v. 19, n. 1, p. 31-38, 2007.

MORALES, Raúl G. Torricella; HOOYDONK, Guido Van; RUIZ, Juan Antonio Araujo. Estudio bibliométrico sobre la presencia de los autores cubanos en el "Web of Science". DataGramaZero, Rio de Janeiro, v. 1, n. 4, 2000.

MOREIRO-GONZÁLEZ, José Antonio. Criterios e indicadores para evaluar la calidad del análisis documental de contenido. Ciência da Informação, Brasília, v. 31, n. 1, p. 53-60, 2002.

MOTTA, Dilza Fonseca da. Validade da análise de citação como indicador de qualidade da produção científica: uma revisão. Ciência da Informação, Brasília, v. 12, n. 1, p. 53-59, 1983.

MUELLER, Suzana Pinheiro Machado. O circulo vicioso que prende os periódicos nacionais. DataGramaZero: Revista de Ciência da Informação, n. 0, dez. 1999. Disponível em: http://www.dgz.org.br/dez99/art_04.htm. Acesso em 15/09/2007.

NUNES, Claudio Omar Iahnke; FREITAS, M. R. M. Exaustividade, Especificidade e Coerência da Indexação da Base de Dados Bibliográficos do NID/FURG (SAB-II). BIBLOS: Revista do Departamento de Biblioteconomia e História, Rio Grande, v. 9, n. 1, p. 155-198, 1997.

ODDONE, Nanci; MEIRELLES, Rodrigo. O Portal de Periódicos da CAPES e os indicadores de desempenho da informação eletrônica. DataGramaZero, Rio de Janeiro, v. 7, n. 3, 2006.

OHIRA, Maria L. B.; SOMBRIO, Márcia L. L. N; PRADO, Noêmia S. Periódicos brasileiros 
especializados em Biblioteconomia e Ciência da Informação: evolução. Encontros Bibli: Revista de Biblioteconomia e Ciência da Informação, Florianópolis, n. 10, out. 2000. Disponível em: <www.ced.ufsc.br/bibliote/ encontro /biblio10> Acesso em: 10/09/2007.

RUMMLER, Guido. Modelagem de um indicador bibliométrico para análise da dispersão de conhecimentos. Ciência da Informação, Brasília, v. 35, n. 1, p. 63-71, 2006.

SANTOS, Gildenir Carolino. Análise do uso da base de dados "Ageline" pelos usuários da Biblioteca Prof. Joel Martins da Faculdade de Educação da UNICAMP de jan.1999 a out. 1999.

Revista Online da Biblioteca Prof. Joel Martins, Campinas, v. 1, n. 1, 1999.

SARACEVIC Tefko, COVI Lisa. for Digital Library Evaluation. In: ANNUAL MEETING 2000 OF THE AMERICAN SOCIETY FOR INFORMATION SCIENCE, 2000. Proceedings... Brunswick, NJ: School of Communication, Information, and Library Studies, Rutgers University, 2000.

SAYÃO, Luís Fernando. Bases de dados: a metáfora da memória científica. Ciência da Informação, Brasília, v. 25, n. 3, p. 314-318, 1996.

STREHL, Leticia. O fator de impacto do ISI e a avaliação da produção científica: aspectos conceituais e metodológicos. Ciência da Informação, Brasília, v. 34, n. 1, p. 19-27, 2005.

UNGER, Roberto J. G.; FREIRE, Isa Maria. Sistemas de informação e linguagens documentárias no contexto dos regimes de informação: um exercício conceitual. Revista Digital de Biblioteconomia \& Ciência da Informação, Campinas , v. 4, n. 1, p. 102-115, jul./dez. 2006.

\begin{abstract}
This work analyses some theoretical issues about database construction, and it is based on practical achievements that were developed during the constitution of a specific information source, the BRAPCI database. It discusses antinomies or oppositions between the formalized and the practiced, adopting as its prior conjecture the need for both criticism and self-criticism, targeted at practice and reflected on the differentiation between the so called quantitative indicators, assessable through the use of quantities, measures and numbers, and the qualitative ones, related to qualities evaluated by the intermediation of constructs. It recommends the complementarity between both of these aspects, when implementing database evaluation processes.
\end{abstract}

KEYWORDS: Databases. Indicators. Information Science.

Originais recebidos em: 08/02/2008

Texto aprovado em:13/03/2008 